\title{
Study on E-commerce Development Strategies of the Special Agro-Products in Jiaozuo City
}

\begin{abstract}
Kang Yanfei
Jiaozuo Teacher's College Jiaozuo City, Henan Province Postal Code:454000

ABSTRACT

The development of agriculture and rural areas have always been the focus of the state, as well as the increase of farmers' income. The application of Internet in agriculture is the need of agricultural development in the new era. Starting from the moving of agricultural products from rural areas to cities, this paper analyzes the current situation and existing problems of the e-commerce development of agricultural products in Jiaozuo city, and analyzes the feasible methods for the e-commerced evelopment of agricultural products in Jiaozuo City, hope to be able to help in jiaozuo E-commerce development on agricultural products.
\end{abstract}

Keywords: E-commerce of rural areas, Current situations, Problems, Strategies

\section{基于焦作市的特色农产品电商发展对策研究}

\author{
康燕飞 \\ 焦作师范高等专科学校 河南 焦作 454000

\begin{abstract}
摘要
农业农村发展, 农民增收一直是国家关注的重点, 互联网在农业方面的应用是新时代农业发展的需要。 本课题以农村电商发展中的农产品上行为切入点, 分析了焦作市农产品电商发展的现状及存在问题, 分析了发展焦作市农产品电商的可行办法，希望能对焦作市农产品电商发展有所帮助。
\end{abstract}

关键词: 农村电商; 现状 问题 路径

\section{1. 前言}

作为农业大国，农业农村的发展，农民的增收一直 是我国的发展大计。“互联网+农业” 的融合发展是 新时代农业发展的需要。针对农村电子商务发展, 国家 出台诸多政策给予鼓励。电商在农村的发展促进了农民 就业创业和农村民生改善, 并助推脱贫攻坚的实现。但 是，作为农业大国，信息不对称、产销对接难等问题仍 制约着我国农村的发展。农村电商的促进了农产品上行, 提高农产品市场竞争力, 提升了农民收入, 但如何进一 步打破时间与空间的桎梏, 更有效推动农村电商的发展 仍有很多问题要解决。

\section{2. 农产品电商对农村经济发展的意义}

\section{1. 农村电商持续助力乡村振兴}

农村电商发展促进乡村产业振兴和人才振兴。2019 中央一号文件聚焦坚持农业农村优先发展, 将 “聚力精 准施策, 决战决胜脱贫攻坚” 作为首发任务。互联网融 合农业是农村精准扶贫的重要平台。发展农村电商, 吸 引外出务工人员回乡创业, 逐步实现 “离土不离乡, 就 业不离家, 打工不外出, 就地脱贫致富”, 助推短期与 长期脱贫目标的完成。焦作市的博爱, 武陟多家电商企 业自身发展同时不忘助力乡村振兴, 积极参与到乡村就 业扶贫工作中, 立足驻地乡村提供扶贫就业岗位, 为走 不出去的劳动力解决了就近就业问题, 缓解了家庭经济 压力, 工作方式也非常灵活, 武陟一家 “飘带” 生产企 业, 工人可以根据自己实际, 将活带回家里做, 赚钱顾 家两不误。 


\section{2. 农村电商向产业链加速延伸}

乡村振兴是实现农业现代化，农民生活富裕，农村 和谐美丽, 从根本上解决新时代 “三农” 问题的重要举 措。没有产业发展的扶贫是无源之水, 无本之木。通过 电商扶贫，产业扶贫等途径，将过去 “救济输血”式扶 贫向 “造血式” 扶贫转变, 实现造血与输血协调发展。 发展农村电商, 推动焦作农产品产业深加工, 形成产业 链条, 培育知名品牌, 推动焦作农产品产业链企业走出 去, 扩大农村就业, 吸引游客, 形成农村发展特色, 助 推乡村振兴的实现。焦作武陟电商企业 “芭米” 利用自 身发展带动带活周边上下游相关产业发展。

\section{3. 焦作市特色农产品电商发展现状及问题}

\section{1. 发展现状}

焦作市按照 “统筹城乡, 突出农村” 的原则, 大力 发展农村电子商务, 目前全市农村电商发展具有初步规 模, 拥有河南省首个农村淘宝试点县, 1 个国家级, 3 个省级电子商务进农村综合示范县, 已建成县级电商服 务中心 5 个, 建成乡级服务站 35 个, 村级网点 1000 余 个。先后出台了《焦作市电子商务发展扶持办法》, 《焦 作市电子商务发展专项资金操作管理办法》等相关政策 支持。深化与阿里菜鸟, 圆通, 中通等物流企业合作, 全面打通农村网络购销, 运输, 配送渠道, 完善物流配 送平台。深入实施 “三品一标” 认证工作, “菡香大米” 获得有机认证, 打造 “怀姜”, “温县铁棍山药” 等农 产品地理认证标志。积极参与农产品标准制订, 制定了 农村电商服务站点标准, 怀姜种植技术等 9 大项电商标 准, 参与或主导制定了 2 个国家级电商标准和 6 个省级 电商标准。

\section{2. 目前存在的问题} 面问题:

焦作市农产品电商发展目前主要存在以下几个方

\subsection{1. 基于电子商务发展的相应政策缺失}

基于电子商务发展的管理体制不明确, 相应政策缺 失, 监管不到位, 导致产品打架, 同业竞争, “李鬼” 打 “李迕”。企业发展面临资金土地问题, 需要相应政 策扶持，营商环境有待提升。

\subsection{2. 商业化运作不足}

农业的发展大多数仍然是沿续传统的农耕意识, 粗 放式的生产销售方式导致农业生产成本过高, 竞争力低
下。“互联网+”下的农业发展要走商业化的运作道路, 适度进行规模化, 组织化, 品牌化的发展, 降低成本, 提升农产品质量, 提升产品认知度。

\subsection{3. 渠道不畅通}

好产品没有好渠道，供需市场信息不对称，渠道不 畅通是农产品上行受阻的主要原因。一方面是城市群体 对新鲜果蔬的急切需求, 一方面是菜农瓜果蔬菜堆积地 头, 销售无路直至烂掉。

\subsection{4. 电商运营人才缺乏}

农村电子商务本质上是借助电子商务规则, 在网络 平台上进行农产品的经营加工和交易。农村电子商务的 发展离不开信息技术, 网络技术, 在应用中需要操盘手 了解懂得一定的技术。目前留守农村的以中老年人为主, 技术实操欠缺, 发展农村电商有心无力。

\section{4. 焦作市特色农产品电商发展对策}

焦作市农产品电商的发展主要应从政策, 产品, 渠 道, 人才这四个方面着手, 探寻农村电商发展之路, 破 解发展瓶颈。

\section{1. 政策因素}

规模化体系化的的农村电商需要有完善的政策体 系的支撑, 政府要明确自身定位, 做到 “不缺位”, “不 越位”, 从政策, 资金, 土地等方面给予企业必要的帮 扶。全国农村电商十大模式之一的 “沙集模式” ，从无 到有, 从弱到强快速发展裂变, 规模之大与当地政府的 扶持理念和做法有很大关系。

\section{1. 1. 理顺政府机制，建立跨部门综合协调 机构}

不同于传统行业的单一发展, 电子商务的发展应用 过程相对复杂, 需要跨行业跨部门的通力配合, 而有能 力协调指挥跨行业跨部门协作的只有政府。目前基于电 子商务发展的政府部门间综合协调机制不完善, “婆婆 多了难办事”, 政府应理顺政府工作管理体制, 建立有 利于电子商务健康发展的制度体系, 在市级层面设立电 子商务的专职管理部门, 减少管理主体数量, 降低协调 成本。政府牵头, 部门联合, 积极推动电子商务综合服 务平台建设, 融入工商, 税务, 统计, 信用等政务服务 功能, 更好的为电商企业和中小网商提供优质服务, 为 
企业发展保驾护航。为解决农产品电商领域比较突出的 是农产品安全标准管理体制不合理问题, 有必要整合分 散在商业、供销及其它部门的农产品质量安全管理职能, 建立一个高效运转、反应迅速的农产品质量安全综合管 理机构, 并授予相应的行政管理职权, 避免多家职能部 门交叉管理、各自为政的体制格局。

\section{1.2. 给予必要的政策扶持}

通过政策引导电商企业间良性竞争, 帮助电商企业 间形成良性竞争, 达到企业利益最大化。农产品的标准 化, 品牌化, 规模化的建设需要企业的努力, 更需要政 策的扶持。标准建立后的落地实施, 品质管控溯源追踪, 品牌建设, 规模发展不是一个企业单枪匹马可以完成的, 需要企业间, 行业协会, 政府部门的联动来协助实现, 而多部门跨行业的联动需要通过政策层面来协调完成。 电商发展的不同阶段, 企业有不同的需求。中小企业有 融资需求, 规模化企业发展有土地需求。资金需求仍是 困扰中小企业发展的重要因素, 在 “重资产, 轻信用” 的贷款条件下, 缺乏有效担保和银行征信记录的农村中 小电商从业者很难获得贷款支持。政府应联合相关部门， 积极探索符合电商特点的信用抵押贷款模式, 对有需求 合条件的中小企业提供资金支持。在目前已有的小微企 业资金扶持基础上，可借鉴 “沙集模式” 中的 “电商助 力贷” , “网商贷” 等方式, 结合焦作的实际情况制定 切实可行的电商企业融资方式。

\section{2. 产品因素}

\section{2. 1. 产品选择}

选择适合电子商务的农产品是农产品电商发展的 基础。首先要确保产品的区域特色, 以稀缺性而获得价 格优势, 从而形成有效竞争力; 其次, 要确保上行的产 品一定要适合在网上销售。焦作具有丰富的农产品资源, 农产品品类种多, 自身特性差异也非常大, 但网络销售 有其自身的特点, 农产品的选择要区别于市场中的正常 消费品。通常情况下, 附加值高且电商难度低的农产品 更适合电商模式。所以对于特色农产品的选择是发展农 产品电商首要解决的问题。

\subsection{2. 商业化运作}

产品选择是基础, 在确定产品之后的商业化运作是 农产品电子商务的助推器。酒香也怕巷子深, 好的产品 借助现代技术和良性运作, 才能在激烈的竞争中立足。 农产品电商要进行商业化运作, 走标准化之路, 严格品 质管控确保产品质量; 运用网络营销手段树立品牌, 打 造品牌。

\subsubsection{1. 标准化生产}

稳定的质量是打造品牌的基石, 生产标准化对于农 产品电商发展起到至关重要的作用, 也是对农产品进行 品质把控的关键。农产品标准化的实质是把农产品本身 以及客户的口味数字化, 让购买者根据各种数字指标选 购商品, 打消消费者网上购买的众多疑虑。农产品标准 化是确保农产品具有稳定质量, 提升农产品竞争力, 保 障农民增收的重要因素。农产品是典型的非标产品, 要 发展农产品电商, 必须要建立实施适当的农产品标准, 走 “标准化”之路, 确保并稳定农产品品质。完善符合 农产品电商发展的标准体系是我国农业现代化进程中 不能回避的重要环节。以标准化生产技术为纽带来规范 分散农户的生产活动，保证农产品品质统一。

推进生产过程的标准化: 按标准组织生产管理是提 高农产品质量, 保证农产品安全最有效的措施和手段, 是稳定消费者消费体验的基石。生产过程 “标准化” 意 味着政府要牵头，携手行业协会，食品监督等相关部门 根据农产品产地和产品品类，建立和实施相应的电商类 农产品标准。质量是产品生命线, 对农产品亦是如此。 目前国内农产品质量参差不齐, 管理的不力致使农产品 的质量不稳定, 随之带来的是消费者体验满意度的缺失, 从而造成消费者的流失。虽然国家也出台了相应的质量 标准, 但能真正落地的不多。农产品企业要坚持做到用 标准去把控质量, 用规程去规范生产, 用标志去树立产 品形象, 用合理手段和方式监测市场。质量管理无死角 无空期, 制定严格的产品质量标准并落地实施, 稳定农 产品内在品质 “1”“褚橙” 电商营销的成功, 除了外 在的因素之外, 关键还是产品自身的严格标准。所有褚 橙不仅要通过严格的生产标准的检验, 更要通过成品标 准的检验, 一枚小小褚橙要想进入市场也是要经过多道 检验确认合格才可以。焦作市在农产品标准引领与建设 方面开展了大量的工作, 制定有怀姜种植技术等相关电 商标准, 为农产品品质保障提供了基础, 关键是标准如 何落地, 这需要企业的努力, 更需要监管部门, 行业协 会的大力协助。

实行农产品质量安全认证: 我国已将农产品质量安 全认证纳入我国农产品质量安全体系建设的基本内容, 将其作为农产品质量安全管理的“切入点”和“突破口”。 在生产过程标准化确保产品质量基础上, 支持新型农业 经营主体加快 “三品” 建设, 申请 “三品一标” 认证。 建立无公害农产品, 绿色食品, 有机食品生产基地, 从 农产品源头入手确保质量安全，好的产品需要有过硬的 质量进行背书才能立身市场。武陟 “菡香大米” 从源头 做起, 构建严格的农产品生产标准, 通过向农户提供统 一的种子及农药, 从产品源头严把质量关, 确保食品安 全及质量。深入实施 “三品一标” 认证, 鼓励帮助有条 件企业申请与产品相关的各类质量体系认证, 建立农产 品质量安全追溯体系。“怀山药”，“怀姜” 等都是焦 作市具有地理认证标志的拳头产品, 但是在企业或产品 运营方面并没有发挥地理认证标志的应有作用, 在确保 产品质量方面还需要大量工作要做。借助地理认证标志 相关机制, 建立质量溯源保护体系, 通过对质量相关的 
关键控制点的数据采集和分析, 实现农产品来有影, 去 有踪, 责任可追究的质量安全管理与风险控制 ${ }^{\mathbf{2} 1}$, 避 免 “只卖码, 不品控” 的现象发展, 确保地理认证标志 及相关标准的落地实施及权威性, 打击 “李鬼” , 保护 “李逵”，为农产品品牌的确立保驾护航。

引入信用体系建设: 建立网上农产品产销供和食品 安全监管信用信息数据库, 增加农产品质量安全信用的 透明度, 促进农产品生产经营企业的行业自律行为, 发 挥行业协会的中介作用, 促进信用体系的进一步完善并 形成良性循环。金融个人征信系统, 司法的失信“老赖” 名单使得失信成本攀升, 失信寸步难行。农产品领域也 可借鉴类似的惩戒体系, 提升违反质量安全相关监管的 企业及责任人的失信成本。

\subsubsection{2. 适度规模化生产}

适度规模化生产以提升市场竞争力。农业规模化发 展, 可以降低生产销售成本, 降低物流成本, 提升产品 的市场竞争力。规模化经营也是实现农业增效和农民增 收的现实保障。中国传统农业的小农式生产模式，使得 农业生产没有形成规模。经济学理中的 “在固定成本不 变的情况下, 商品生产数量越多, 成本越低” 的理论也 同样适用于农产品电商。农村电商的推进基础是要先形 成规模经济, 积极探索和促进焦作农产品种植规模化和 农场化, 扩展上下游产业链, 提升市场竞争力。在有条 件的地区, 结合地区农产品优势, 以土地流转形式扶持 农户进行规模化经营。引导和鼓励农业龙头企业、农民 专业合作社、专业农户参与规模化经营; 构建农产品电 商产业链, 借助标准化过程, 将单个的电商经营主体连 通起来, 实现一定程度的规模化, 组织化生产, 反过来 也能进一步促进物流体系的建设和完善 ${ }^{\mathbf{I} 1}$ 。

\subsubsection{3. 树立品牌}

树立农产品品牌, 提升市场辨识度。农产品品牌化 发展道路不仅是现代农业的发展趋势和必然选择, 也是 提升市场竞争力、满足消费者需求的重要手段。当前农 产品的市场竞争, 已经从传统的农产品本身的竞争延伸 到了农产品品牌文化和品牌价值的竞争。农产品电商品 牌建设要从准确的品牌定位开始, 做好区域品牌的传播 和保护, 通过整合线上线下资源打造品牌系统工程, 树 立农产品品牌, 最大程度提高产品的曝光度和认知度。 对适合上行的农产品进行品牌捊化, 提升特色农产品品 质, 加强营销宣传力度, 提升产品质量, 树立品牌意识。 有条件的地区可以确立品牌双线制，即基于地理认证基 础上的区域品牌及农户自有品牌。品牌营销, 质量先行, 没有质量保证的产品如同无源之水。品牌意味着与其价 格相符的质量承诺。农产品对于特定地域的土壤、气候 条件等生长环境有着高度依赖性, 脱离了该特定生长环 境就不再成为该特色农产品。所以对农产品的品牌保护 就要求对原产地进行严格的保护, 确保农产品的 “特” 字 ${ }^{\mathbf{4} 】}$ 。
因技术含量较低而容易被假冒，导致伪劣产品多。 企业自身防范不正当竞争行为的成本高、效果差。政府 及其职能主管部门是行政执法责任人，要承担起打假任 务, 加大对假冒行为的打击力度, 全面保护农产品品牌, 营造农产品品牌运作的良好环境。政府应制定相关政策 防止企业农产品品牌的盗用冒用, 加大对假冒农产品品 牌行为的打击力度。加大对于那些乐于 “搭便车” 而不 愿意投资品牌建设的企业的处罚力度。

利用政府行为加大品牌宣传推广力度。消费者对政 府的信任是农产品品牌能够快速推广与发展的重要条 件。利用政府信誉为农产品品牌在乡土文化与时代性品 牌诉求上承担信誉保证, 为本地优质农产品品牌背书, 武陟县长为 “武陟菡香” 站台宣传就是很实在的例子。 以“政府搭台，企业唱戏”的方式，推广农产品，从而 减少消费者的认知成本与认知风险, 用简单而粗暴的方 法占据消费者有限的心智, 实现品牌的跨越式发展。

开展生态旅游和观光旅游, 充分利用焦作的区位优 势和旅游资源, 打造 “旅游+农业” 的品牌推广模式, 提升焦作农产品品牌的市场认可度, 利用游客口碑宣传 成本更低、效果更好。利用良好的生态环境，在旅游资 源丰富的地区, 通过和旅游业的战略合作, 借助景点的 高流量扩大农产品的域外知名度, 让游客亲身感受到农 产品产地的良好环境, 在参与农事活动过程中, 了解无 公害农产品、绿色农产品、有机农产品的生产环境和生 产过程，坚定游客对高品质农产品的消费者信心。

\section{3. 渠道因素}

市场需要好产品, 好产品需要走出去, 信息渠道, 上行渠道要畅通。农产品电商要在信息和流通渠道上有 进一步的拓展。

\section{3. 1. 建设农产品信息商务平台}

农产品的产需具有明显的信息不对称性, 这一问题 不能有效解决，容易导致农产品生产陷入 “柠檬市场” 困境, 损伤农户利益 ${ }^{\mathbf{5 1}}$ 。建设农产品信息商务平台, 扩展信息渠道; 加强对农业信息的采集, 发布和传播, 提高市场透明度。这需要政府部门, 行业协会联手向农 户进行农产品供需信息推送。

\subsection{2. 完善供应链体系建设, 开拓多元化渠 道}

农产品上行难一个重要原因是供应链体系不健全, 产品供应上没有 “根据地” ，长期处于 “游击” 状态， 不利于农产品电商的长期长远发展。没有完善的供应链 的企业或产业在未来电商发展竞争中很难立足。义乌的 小商品城, 沙集的简易家具生产基地都对当地电子商务 发展起到了重要支撑作用。可以通过建设诸如焦作农特 
产品交易中心等以完备焦作市农产品电商供应链体系， 打通农产品上行渠道。

在现在上行渠道基础上, 积极寻求开拓元化渠道。 农产品品类不同, 产品定位不同, 上行渠道都会有所差 别。目前农产品流通主要以农贸市场, 农产品批发市场, 大型连锁超市及小型生鲜专卖店等为载体, 形成了 “农 民一农产品批发市场一零售商一消费者” 的主要流通模 式。积极开拓建立与第三方供销平台的战略合作, 采取 农户自行入驻模式, 区域商城模式, 不仅要走传统小规 模的 B2C 模式, 更要尝试规模化的 B2B 平台模式以及专 注农产品的生鲜电商平台，多管齐下，让农产品从田间 走向市场 ${ }^{\mathbf{6}]}$ 。

\section{4. 人才因素}

注重人才培养, 特别是本土人才的培养。电子商务 产业不同于传统农业, 是属于智力密集型产业, 对于人 才的知识和素质都有较高的要求。农村电商的发展离不 开构建信息共享, 金融服务, 智能物流, 监管防控等配 套服务体系, 更离不开人才支撑体系。专业人才短缺也 是目前农村电商发展面临的共同瓶颈, 制约农村地区电 子商务应用发展的关键在于 “人才不足”。注重电商人 才的培养, 从源头解决农村电商发展突出问题。目前, 很多农村电商企业对于一些高端人才需求主要通过 “请 进来” 或代运营模式来解决。但从长远发展着眼, 农村 电商的发展还是要注重本土电商人才的培养。充分利用 本地教育资源, 行业培训机构的作用, 加快电子商务基 础人才培育。

\subsection{1. 加强对基层领导干部的培训, 提高农} 村基层领导对电子商务的认识。基层领导工作主 要是在农村, 他们是农村电子商务发展的关键, 给予农 村基层领导更多学习电子商务知识和技能的机会, 从而 让他们在开展电子商务工作中不断更新工作理念, 创新 工作方法, 提高整体管理水平。博爱, 武陟电子商务的 业绩取得离不开领导对电子商务认知认同。

\subsection{2. 鼓励本土大学生返乡创业以及外出务} 工青年回乡就业，农村劳动力外出务工导致了老人 村, 留守儿童问题的出现。鼓励本土大学生返乡创业, 引导电子商务人才不断回流, 这也是解决目前农村社会 形态的有效途径。博爱县的 “县长喊你回家做电商”已 经成为广大青年返乡创业的集结号, 吸引了一批在外 打拼的博爱籍成功人士回家乡创业, 博爱县精心谋划为 电商培育的沃土, 还让本土商家纷纷转型 “触网” 从而 变得强大。

\section{5. 小结}

农村电商的发展是 “工业品下行”和“农产品上行” 的齐头并进，不能跛脚前行。做好 “农产品上行”，带 动农户钱袋子鼓起来, 才能为 “工业品下行” 走得稳, 走得远提供实在的支持。要通过政府扶持, 质量提升, 品牌打造, 人才培育, 为农村电商发展铺好路, 把好脉, 引领农产品走出去, 站得住, 叫得响。焦作市有着丰富 的农产品资源, 有着良好的农村电商的基础, 通过不断 的政策支持，人才培养，辅之适度的商业化运作，仍有 无限潜力。

\section{REFERENCES}

[1] Chen Debao, Analysis on the Ascending Problems and Countermeasures of Agricultural Products E-commerce. [J] Chinese Market, 2019(07):181-182+184.

[2] Zhou Cuiqing, Mobile e-commerce marketing model on special agricultural products, [J] Modern Marketing, 2018(08):112-113.

[3] Zhu Haibo, Zhang Xuebiao, Research on the Development Path Selection of Agricultural Products E-commerce in poor areas from the perspective of industrial chain Remodelin, [J], Chinese Foods \& Nuturion, 2018,24(03):39-43.

[4] Sun Zhengli, Research on the development Mode of agricultural Products e-commerce in Gansu Province, Paper on Master Degree, 2018

[5] Zhao Yu, Wang Xiaohong, Problems and countermeasures of agricultural product quality safety traceability system construction, [J], The Farmers' Friend, 2019(01):233.

[6] Sun Jinli, The choice of electronic commerce mode of agricultural products in China, [J] Business modernization 